RESEARCH PAPER

\title{
Cluster Analysis of Quality Characteristics of Seedling Mango Fruits Collected from Different Locations of Himachal Pradesh, India for the Development of Pickle
}

\author{
N.S. Thakur ${ }^{1}$, Dharmender Kumar ${ }^{1}$, V.K. Joshi ${ }^{2}$, Abhimanyu Thakur ${ }^{1 *}$ and \\ Hamid $^{1}$
}

${ }^{1}$ Department of Food Science and Technology, Dr YS Parmar University of Horticulture and Forestry, Nauni, Solan, HP., India

${ }^{2}$ Formerly of Department of Food Science and Technology, Dr YS Parmar University of Horticulture and Forestry, Nauni, Solan, HP., India

*Corresponding author: abhimanyuthakurprashar@gmail.com

Paper No.: 235

Received: 02-06-2019

Revised: 08-09-2019

Accepted: 20-11-2019

\begin{abstract}
Seedling mango (Mangifera indica L.) fruit is one of the important wild fruits which have got commercial importance due to its utilization in pickle preparation and other culinary purpose. In Himachal Pradesh (HP), it is widely distributed in the lower hills and plain areas with significant difference in the quality characteristics of fruits from location to location. The fruits of seedling mango were harvested from 24 different locations of six districts (Kangra, Una, Hamirpur, Bilaspur, Mandi and Sirmour) of HP and the results of their physical, chemical, sensory, physico-chemical and combined physicochemical and sensory characteristics were analyzed using cluster analysis (SPSS). On the basis of this analysis of quality characteristics including higher acid-edible content indicator (2.36) and sensory quality, fruits of 10 locations were found suitable for pickle preparation viz. Kangra (Sulah and Bhawarna), Una (Una Sadar and Amb), Hamirpur (Bhoranj), Bilaspur (Ghumarwin), Mandi (Gopalpur and Pandoh) and Sirmour (Nahan and Ponta Sahib).
\end{abstract}

Keywords: Cluster analysis, Locations, Pickle, Quality, Seedling mango

Mango (Mangifera indica L.) known as the king of fruits is one of the popular tropical fruits which belong to family Anacardiaceae. The other edible species belonging to genus are commonly known as wild mango or seedling mango. The wild forms are found in various countries like Malaysia, Indonesia, Malaya, Borneo, Sumatra, India, China, Mexico, Pakistan, Nigeria, Thailand, South Central America, Philippines, Brazil, Australia and Egypt (Kumar et al. 2001 and Singh et al. 2016). In India, the wild forms are widely distributed throughout the subtropical Himalayas, hills of Western and
Eastern Ghats and in lower hills or plain areas of Himachal Pradesh (Singh et al. 2009 and Thakur et al. 2017a). Seedling mango fruit is a rich source of various nutrients like carbohydrates, vitamins, organic acids, fibres, proteins, fats and minerals like potassium, magnesium, sodium, phosphorous and sulphur (Knight, 1997 and Singh et al. 2012).

How to cite this article: Thakur, N.S., Kumar, D., Joshi, V.K., Thakur, A. and Hamid (2019). Cluster Analysis of Quality Characteristics of Seedling Mango Fruits Collected from Different Locations of Himachal Pradesh, India for the Development of Pickle. Int. J. Food Ferment. Technol., 9(2) $117-123$.

Source of Support: None; Conflict of Interest: None 
Thakur et al.

These nutrients along with other antioxidants are known to have beneficial effect against nutritional and neurodegenerative disorders such as beri-beri, bronchial disorders, kidney stones, insomnia, brain fatigue, mental depression, Alzheimer's disease and strengthen the immune system (Singh et al. 2009; Kashyap et al. 2017 and Thakur et al. 2019). Due to the acidic taste, wild mango fruits are utilized for the culinary purpose and mostly for the pickle preparation in India (Thakur et al. 2017b). Because of the greater variation in the quality characteristics of wild mango fruits collected from different locations of HP, cluster analysis of quality characteristics was carried out for the preliminary selection of the mango fruits for pickle preparation.

\section{MATERIALS AND METHODS}

Procurement of raw material: The mature green fruits of seedling mango were harvested from six districts (24 different locations) of Himachal Pradesh given in Fig. 1.

\section{Physico-chemical and sensory characteristics}

The length and diameter of fruit samples were measured with the help of digital vernier calliper whereas, digital weighing balance was used to weigh the fruit samples. Water displacement method was used to determine fruit volume and weight divided by volume of fruit gave specific gravity of fruit. The edible content and stone content of the samples were observed on weight basis (\%). Moisture, TSS, sugars, titratable acidity, ascorbic acid, chlorophyll, starch and ash content of samples were determined according to the standard methods (Ranganna, 2009). The $\mathrm{pH}$ of fruits was determined by using a digital $\mathrm{pH}$ meter (CRISON Instrument, Ltd, Spain). Total phenols and crude fibre content of fruit samples were determined by standard procedures (Singleton and Rossi, 1965 and Gould, 1978). The sensory evaluation of samples was carried out by hedonic rating test and the samples were evaluated for sensory qualities based on appearance, texture, taste and overall

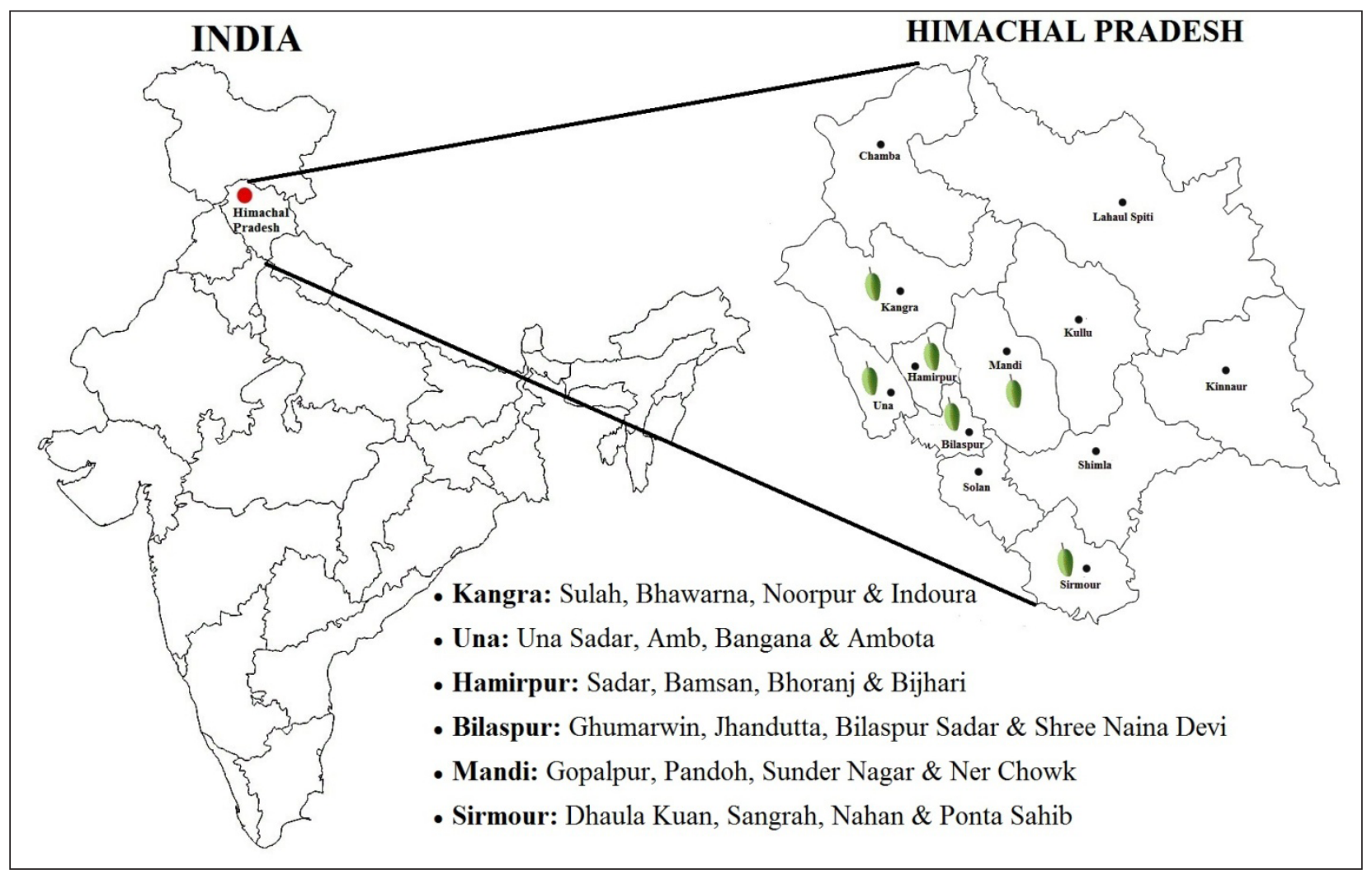

Fig. 1: Map of the locations for procurement of seedling mango fruits 
acceptability (Joshi, 2006). The data for cluster analysis was adapted from Thakur et al. (2017c).

Cluster analysis: The physical, chemical, sensory, physico-chemical and combined physico-chemical and sensory characteristics of 24 locations were analyzed by cluster analysis (SPSS). The technique is a multivariate technique and is capable of clustering the samples or varieties with similar characteristics into group(s).

Cluster analysis of the samples from different locations of HP was performed using rescaled distance cluster with respect to physical parameters, chemical parameters and sensory characteristics individually, physico-chemical combined and physico-chemical and sensory scores characteristics combined together.

Based on different parameters of fruits of different locations separate clusters were formed as discussed in the Results and Discussion.

\section{RESULTS AND DISCUSSION}

Cluster analysis of physico-chemical and sensory characteristics of seedling mango fruits

Cluster analysis of the samples from different locations of HP was performed and the results obtained have been presented in Fig. 2-6. On the basis of Dendrogram of physical characteristics (Fig. 2) the locations have been separated into two broad clusters with 10 ( 7 and 3 locations in subclusters) and 14 locations (4, 5 and 5 locations in sub clusters), respectively. Cluster analysis of chemical characteristics (Fig. 3) however reveals that locations were separated into two broad clusters with $18(3,2,3$, 2, 2, 2, 4 and 3 locations in sub clusters) and 6 locations ( 2 and 4 locations in sub clusters), respectively. The Dendrogram in Fig. 4 shows that 24 locations were separated into two broad clusters with 10 (5 locations in 2 sub clusters) and 14 locations ( 4,6 and 4 locations in sub clusters), respectively on the basis of

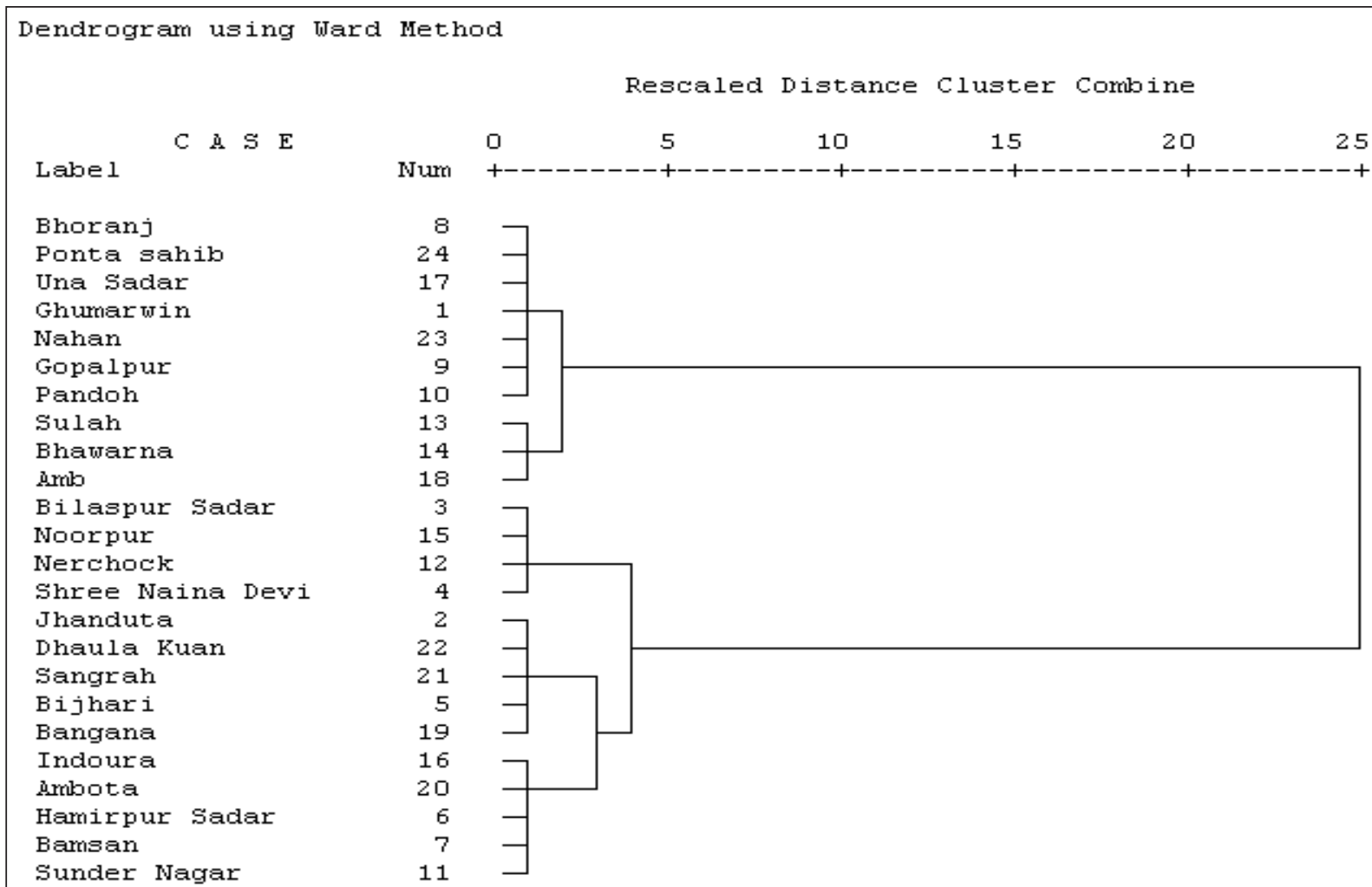

Fig. 2: Dendrogram of physical characteristics of seedling mango fruits of different locations of HP 
Thakur et al.

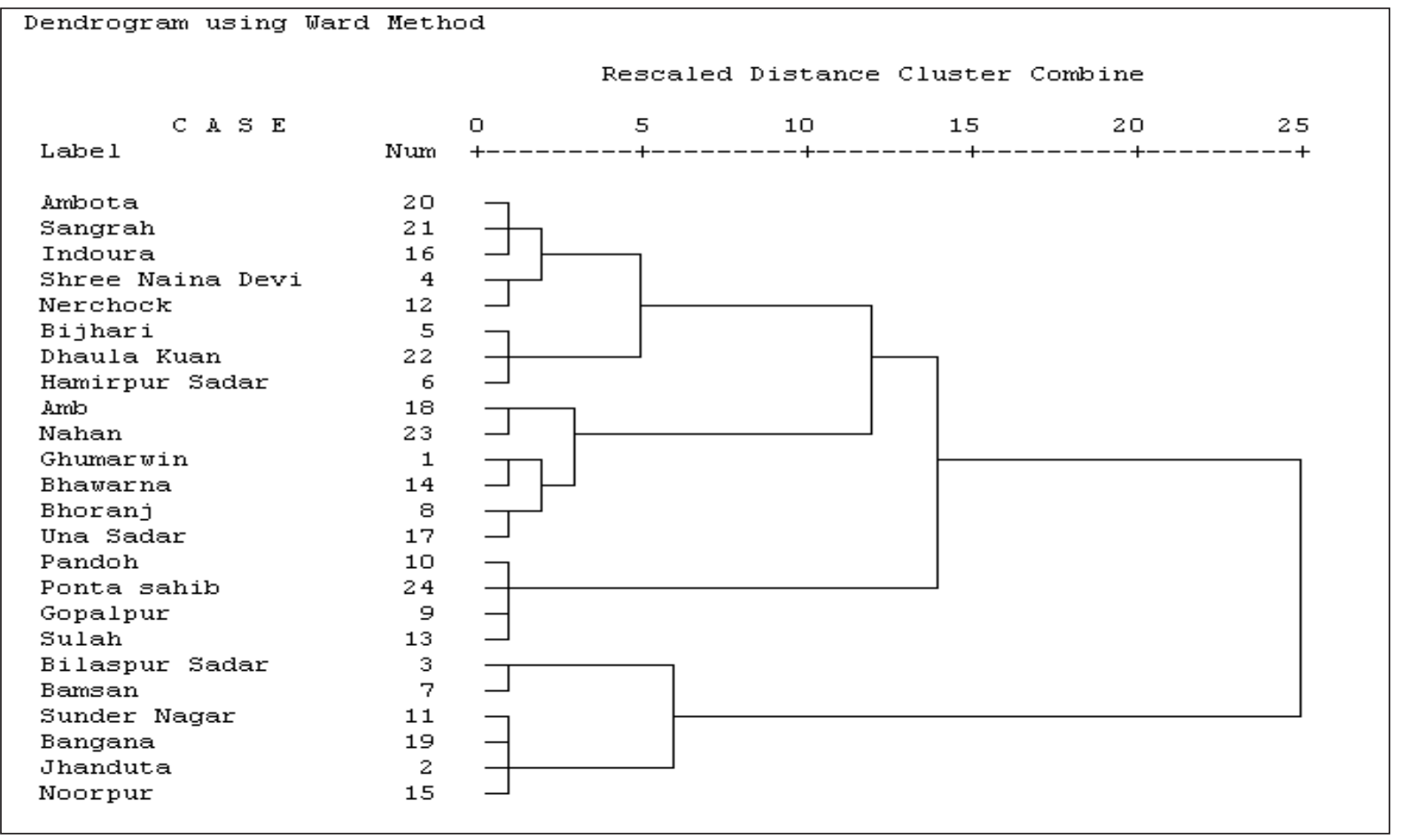

Fig. 3: Dendrogram of chemical characteristics of seedling mango fruits of different locations of HP

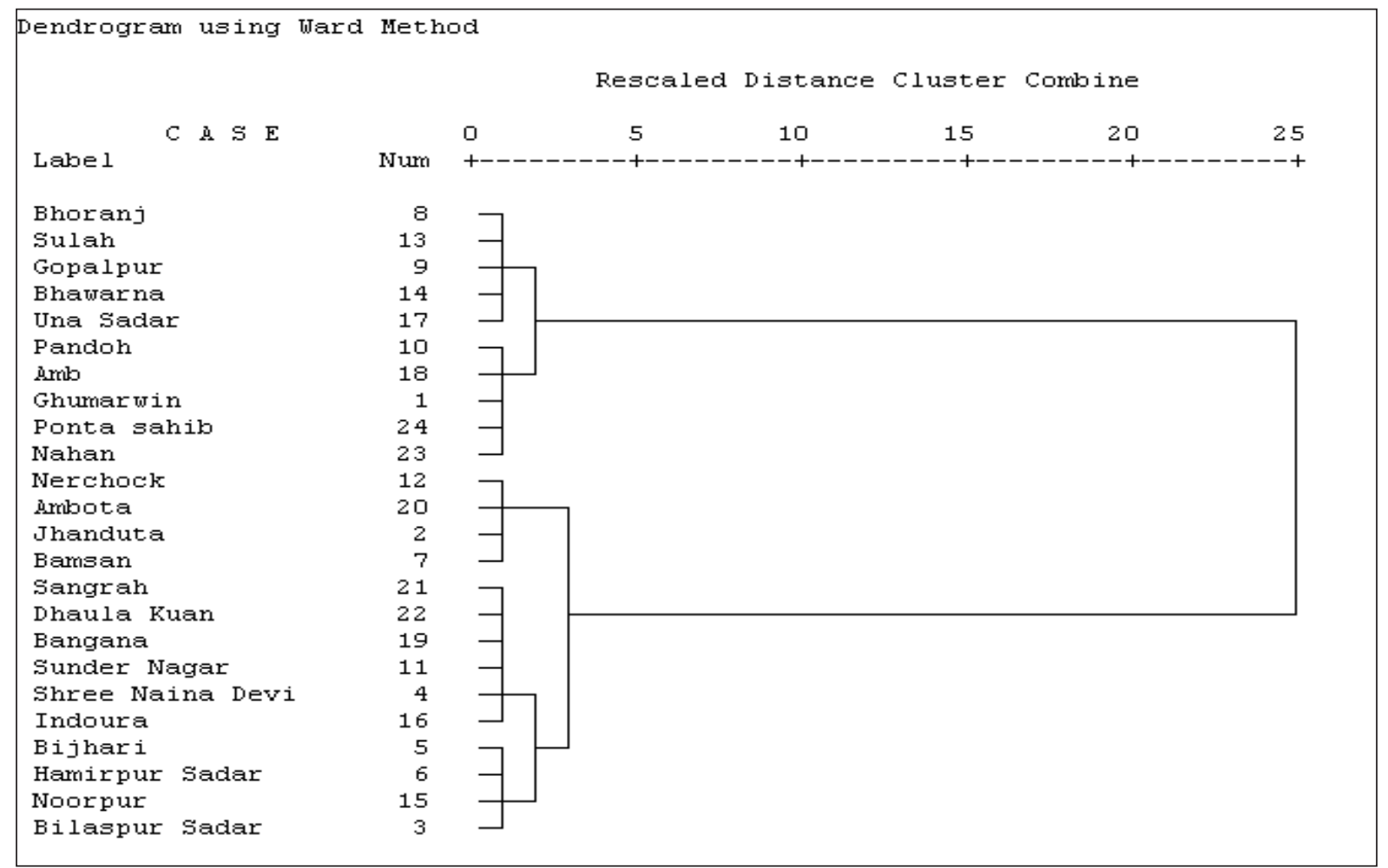

Fig. 4: Dendrogram of sensory characteristics score of seedling mango fruits of different locations of HP 
Cluster Analysis of Quality Characteristics of Seedling Mango Fruits Collected from Different... \&



Fig. 5: Dendrogram of physico-chemical characteristics of seedling mango fruits of different locations of HP



Fig. 6: Dendrogram of physico-chemical and sensory characteristics score of seedling mango fruits of different locations of $\mathrm{HP}$ 
sensory characteristics. On the basis of Dendrogram of physico-chemical characteristics and physicochemical and sensory characteristics (Fig. 5 and 6) the locations were separated into two broad clusters with 10 (4, 2 and 4 locations in sub clusters) and 14 locations (3, 3, 2, 2 and 4 locations in sub clusters), respectively. It is apparent that cluster analysis of physical and chemical characteristics individually didn't separate the different locations in distinct clusters. However, it is very much clear that cluster analysis has successfully separated distinct locations in different clusters based upon physico-chemical and physico-chemical sensory characteristics of fruits. The cluster analysis has broadly separated the locations into two clusters shown as cluster-1 (Gopalpur, Bhoranj, Ghumarwin, Pandoh, Sulah, Bhawarna, Una Sadar, Amb, Nahan and Ponta Sahib) and cluster-2 (Noorpur, Indoura, Bangana, Ambota, Hamirpur Sadar, Bamsan, Bijhari, Jhandutta, Bilaspur Sadar, Shree Naina Devi, Sunder Nagar, Ner Chowk, Dhaula Kuan and Sangrah). Based on the acid-edible content indicator as well as the cluster analysis of physical; chemical; sensory; physico-chemical; and physico-chemical and sensory; characteristics, fruits from the locations of cluster-1 were selected.

Similar to these results cluster analysis has successfully been employed to separate different isolates, products or locations based upon their physico-chemical and sensory characteristics (Headly et al. 1989). Cluster analysis (multivariate technique) separated the similar groups based on different physico-chemical and sensory characteristics in the form of dendrogram (Kaiser, 1960 and Ludwig et al. 1988). So, on the basis of cluster analysis of data of physico-chemical, sensory characteristics scores and acid-edible content indicator, fruits of 10 locations viz. Gopalpur, Bhoranj, Ghumarwin, Pandoh, Sulah, Bhawarna, Una Sadar, Amb, Nahan and Ponta Sahib were selected.

\section{CONCLUSION}

Out of 24 locations, fruits from 10 locations were selected preliminarily on the basis of cluster analysis of some physico-chemical and sensory characteristics.
These locations were Gopalpur, Bhoranj, Ghumarwin, Pandoh, Sulah, Bhawarna, Una Sadar, Amb, Nahan and Ponta Sahib from the major wild mango growing districts of Himachal Pradesh

\section{REFERENCES}

Gould, W.A. 1978. Food quality assurance. The Avi Publishing Company, Westport, Connecticut, pp. 314.

Headly, L.M. and Hardy, J.K. 1989. Classification of whiskies by principal component analysis. Journal of Food Science, 54(5): 1351-1354.

Joshi, V.K. 2006. Sensory Science: Principles and Applications in Evaluation of Food. Agro-Tech Publishers, Udaipur, pp. 527 + Plates, Figs.

Kaiser, H.F. 1960. The applications of electronic computers in factor analysis. Education Psychological Measurement, 20(1): 141-155.

Kashyap, P., Anand, S. and Thakur, A. 2017. Evaluation of antioxidant and antimicrobial activity of Rhododendron arboreum flowers extract. International Journal of Food and Fermentation Technology, 7(1): 123-128.

Knight, R.J. 1997. Important mango cultivars and their description. In: Mango Botany Production and Uses. CAB International Wallingford Oxan, UK, pp 545-565.

Kumar, H.N.V., Narayanswamy, P., Theertha, P.D., Mukund, G.K. and Sondur, S. 2001. Estimation of genetic diversity of commercial mango cultivar using RAPD markers. Journal of Horticultural Science and Technology, 76(5): 529-533.

Ludwig, A.J. and Reynlids, J.F. 1988. Statistical ecology: A primer on methods and computring, pp. 189-241.

Ranganna, S. 2009. Handbook of analysis and quality control for fruit and vegetable products. Tata McGraw Hill, New Delhi, 1112p.

Singh, N.K., Mahato, A.K., Jayaswal, P.K., Singh, A., Singh, S. et al. 2016. Origin, Diversity and Genome Sequence of Mango (Mangifera indica L.). Indian Journal of History of Science, 51(2): 355-368.

Singh, N.P., Jerath, N., Singh, G. and Gill, P.S. 2012. Physicochemical characteristics of unexploited mango diversity in sub-mountainous zone of North India. Indian Journal of Plant Genetic Resources, 25(3): 226-269.

Singh, S.K., Sharma, V.K., Kumar, Y., Kumar, S.S. and Sinha, S.K. 2009. Phytochemical and pharmacological investigations on mangiferin. Herba Polonica, 55(1): 126-139.

Singleton, V.L. and Rossi, J.A. 1965. Colorimetry of total phenolics with phosphomolybedic phosphotungstic acid reagent. American Journal of Enology and Viticulture, 16: 144158.

Thakur, N.S., Kumar, D., Thakur, A., Chauhan, M. and Kumar, P. 2017b. Studies on development and storage quality of 
Cluster Analysis of Quality Characteristics of Seedling Mango Fruits Collected from Different... e P

seedling mango (Mangifera indica L.) pickle of Himachal Pradesh. Indian Journal of Ecology, 44(6): 690-696.

Thakur, A., Joshi, V.K. and Thakur, N.S. 2019. Immunology and its relation with food components: an overview. International Journal of Food and Fermentation Technology, 9(1): $1-16$

Thakur, N.S., Kumar, D., Thakur, A. and Hamid. 2017c. Studies on quality characteristics of seedling mango fruits from different locations of Himachal Pradesh. Journal of Hill Agriculture, 8(3): 288-292.
Thakur, N.S., Kumar, D., Thakur, A. and Kumar P. 2017a. Studies on changes in quality characteristics of brined seedling mango pieces during storage. International Journal of Current Microbiology and Applied Sciences, 6(9): 655-664. 
